\title{
LEANDRA, MARCELA Y MARITORNES. APUNTES \\ SOBRE LA EVOLUCIÓN DE LA MATERIA PASTORIL EN EL PROCESO CREATIVO DEL QUIJOTE
}

CARLOS ANSÓ

Università di Pisa

Una de las cosas que más nos chocan cuando abordamos en el Quijote de 1605 la materia pastoril es la enorme distancia que media entre los episodios contenidos en los capítulos XI, XII, XIII y XIV de la obra, en donde, entre otras cosas, se nos cuenta la historia de Grisóstomo y Marcela, y la aparición en el capítulo L del cabrero Eugenio, que sólo en el capítulo siguiente nos narra la historia de Leandra, su fuga con el soldado Vicente de la Roca y el consiguiente desplante que reciben sus dos pretendientes oficiales; es decir, el propio Eugenio y su amigo Anselmo.

Sin embargo, no sólo es esto lo que nos choca cuando consideramos la materia pastoril en su conjunto. Igualmente chocantes nos resultan, si no más todavía, las vistosas semejanzas que mantienen entre sí algunas zonas de estas dos historias; semejanzas que se imponen, sobre todo, cuando ponemos frente a frente a los dos personajes femeninos, es decir a Marcela y a Leandra.

En efecto: ambas son hijas de labradores ricos; ambas son bellísimas; ambas son adolescentes cuando ya, en los dos casos, la fama de su belleza ha superado con mucho los límites de su aldea; ambas son huérfanas (Marcela de padre y madre y Leandra de madre); ambas dependen, pues, de un adulto varón (Marcela de su tío y Leandra de su padre); ambas reciben propuestas de matrimonio por parte de gente de su pueblo y de otros sitios; ambas deciden darle largas al asunto, y ambas, en fin, sin previo aviso, se marchan de su casa.

¿Cómo interpretar toda esta serie de coincidencias que difícilmente podríamos considerar casuales? - nos preguntamos-. $\mathrm{O}$, en otras palabras: ¿cuál pudo ser la intención que movió a Cervantes 
a trazar todos estos paralelismos entre los dos personajes? En nuestra opinión, la respuesta más cabal emerge de la lectura del conjunto de sus historias; historias que si hasta aquí se presentan como prácticamente idénticas, a partir de este momento siguen un recorrido diametralmente opuesto, ya que si por un lado Leandra escapa cediendo a los requerimientos de Vicente de la Roca para entregarse a él la primera noche de su fuga - motivo por el que luego acabará encerrada en un monasterio-, Marcela hace de la libertad obtenida escapando de su casa el terreno más propicio para afirmar su honestidad; una honestidad que no sólo mantiene sin fisuras frente al enamoramiento apasionado de Grisóstomo, sino que además, como si de un círculo virtuoso se tratara, le permite - por oposición a la desenvoltura con que se comporta Leandra, a quien, por lo demás, su amante encierra en una cueva- seguir viviendo al aire libre y mantener intacta su libertad.

Lo primero que salta a la vista, pues, cuando comparamos estas figuras es que Cervantes las enfrenta a un mismo problema: el del viejo conflicto entre libertad y moralidad sexual. Lo segundo se deduce de este hecho y en realidad constituye la única respuesta plausible que hallamos a la pregunta que nos hacíamos arriba; y es que Cervantes parece haber trazado todos esos paralelismos iniciales entre ellas con el único objetivo de subrayar sus divergencias; es decir, para recalcar de este modo: a) los distintos comportamientos por los que optan una y otra ante idéntico problema, y b) los diferentes lugares a que ambos comportamientos las conducen; donde no nos será difícil ver, por un lado, el castigo que conlleva la conducta de Leandra, y, por otro, el premio que Marcela recibe por su virtud.

Es como si, al abordar la escritura de estas páginas tan distantes, Cervantes hubiera querido partir de un planteamiento común para recordar al lector que ambas historias no son sino la cara y la cruz de una misma moneda; es decir, las versiones complementarias, y ejemplares, de una misma lección.

Esto por lo que se refiere a las protagonistas.

$\mathrm{Y}$, sin embargo, los paralelismos que mantienen los planteamientos de estas dos historias no acaban aquí, pues también las actitudes que adoptan el tío de Marcela y el padre de Leandra ante las propuestas matrimoniales que reciben las muchachas son idénticas. Veámoslo. Leemos en el caso de Marcela:

Con estas que daba, al parecer, justas excusas, dejaba el tío de importunarla y esperaba a que entrase algo más en edad y ella supiese escoger compañía a su gusto. Porque decía él, y decía muy bien, que no habían de dar los padres a sus hijos estado contra su voluntad. 
Lo mismo leemos en la historia de Leandra, cuyo padre le comunica las propuestas

advirtiendo que [...] era bien dejar a la voluntad de su querida hija el escoger a su gusto; cosa digna de imitar de todos los padres que a sus hijos quieren poner en estado.

¿Cómo interpretar este nuevo paralelismo? Pues, evidentemente, del mismo modo en que hemos interpretado los otros, ya que, en realidad, los refuerza. Ahora bien: si releemos con atención los fragmentos apenas citados, obsevaremos, todavía, una nueva coincidencia: la que emerge de la actitud de los dos narradores, ya que, cada uno en su relato, al refererir el comportamiento de tío y padre respectivamente, manifiestan explícitamente su conformidad con él.

¿Qué decir de esta última simetría? ¿Que también está orientada a reforzar el carácter complementario de estas páginas? Puede ser. Y sin embargo, el hecho de que toda esa serie de paralelismos que señalamos abarque aspectos que bien podríamos considerar de detalle produce en nosotros una nueva impresión: la impresión de que, para obtener el efecto descrito, Cervantes hubiera empezado a escribir una de estas historias, no recordando tan sólo, sino teniendo a la vista la otra; es decir, parafraseándola.

La pregunta que nos hacemos ahora es, pues, la siguiente: ¿cuál de ellas pudo servir de modelo — si bien parcial- y cuál puede ser la copia? La cuestión no es tan gratuita como podría parecer a primera vista, pues de la respuesta que obtengamos podrían emerger valiosas indicaciones sobre el método de trabajo de Cervantes; indicaciones que bien podrían iluminar aspectos de esa especie de dinamismo implícito que subyace a muchos de los motivos y temas que aparecen en el Quijote y que parte de la crítica ha definido como relativismo.

Así, pues, siguiendo con el análisis de estos dos relatos, nos detendremos ahora en lo que definiremos sus anomalías; anomalías que, si bien en su momento ya analizó —en nuestra opinión más que acertadamente- José Manuel Martín Morán ${ }^{1}$, nosotros volveremos a analizar, añadiendo nuevos detalles, con el único fin de no interrumpir aquí el hilo de nuestras argumentaciones.

Para empezar señalaremos, pues, la más conocida y comentada de todas; es decir, la falta de adherencia narrativa que muestra la "canción desesperada» de Grisóstomo respecto al resto del relato de su historia con Marcela. En efecto: hasta tal punto es evidente dicha falta de adherencia, que cuando Vivaldo lee la can-

${ }^{1}$ El Quijote en ciernes, Turín, 1990, pp. 100-105. 
ción en voz alta y la pone de manifieto - ya que, según dice textualmente, «en ella se quejaba Grisóstomo de celos, sospechas y de ausencia» (cosas todas ellas fuera de lugar, pues Marcela se limita a rechazarlo)_-, Ambrosio se ve en la obligación de explicar y justificar lo que de otro modo podría aparecer como un puro delirio de su amigo con las siguientes palabras:

\begin{abstract}
Para que, señor, os satisfagáis desa duda, es bien que sepáis que cuando este desdichado escribió esta canción estaba ausente de Marcela, de quien él se había ausentado por su voluntad, por ver si usaba con él la ausencia de sus ordinarios fueros; y como al enamorado ausente no hay cosa que no le fatigue ni temor que no le dé alcance, así le fatigaban a Grisóstomo los celos imaginados y las sospechas temidas como si fueran verdaderas. Y con esto queda en su punto la verdad que la fama pregona de la bondad de Marcela; la cual, fuera de ser cruel, y un poco arrogante, y un mucho desdeñosa, la mesma envidia ni debe ni puede ponerle falta alguna.
\end{abstract}

Palabras donde cualquier lector mínimamente agudo podrá observar, no sólo el dudoso resultado que Ambrosio obtiene con ellas, sino la evidente sutura textual realizada aquí por Cervantes para introducir en el relato una pieza poética preexistente -es decir, ajena a él-y cuyo único nexo convincente con la historia parece ser esa amenaza de suicidio que contiene y que anticipa la trágica muerte de Grisóstomo².

Pero, a propósito de desenlaces trágicos; centrémonos ahora en la historia de Leandra y escuchemos lo que dice el narrador, que -recordémoslo- es uno de sus pretendientes:

llámase mi competidor Anselmo, y yo Eugenio, porque vais con noticia de los nombres de las personas que en esta tragedia se contienen, cuyo fin aún está pendiente; pero bien se deja entender que ha de ser desastrado.

Obsérvese, pues, no sólo cómo Eugenio califica la historia de tragedia - lo cual implicaría, como en la de Grisóstomo y Marcela, un final con muerto-, sino cómo corrige inmediatamente el tiro y matiza la expresión diciendo que aún no tiene un desenlace; palabras que, evidentemente, no parecen referidas a sí mismo, al menos si leemos lo que, contraponiendo su actitud a la de Anselmo, nos dice al final de su relato:

Yo sigo otro camino más fácil, y a mi parecer el más acertado, que es decir mal de la ligereza de las mujeres, de su inconstancia, de su doble

${ }^{2}$ Lo mismo afirma JuAn BaUtista Avalle-ARCE en Nuevos deslindes cervantinos, Barcelona, 1975, p. 95. 
trato, de sus promesas muertas, de su fe rompida, $y$, finalmente, del poco discurso que tienen en saber colocar sus pensamientos e intenciones que tienen.

Por lo que es, pues, evidente que cuando predice el «fin desastrado» de la historia que está a punto de contar, Eugenio sólo puede referirse a la otra víctima de la desenvoltura de Leandra; es decir, a su rival y amigo Anselmo.

Ahora bien: veamos qué nos dice de él. Después de haber descrito cómo - una vez que el padre encuentra a la muchacha y la encierra en un monasterio- todos aquellos parajes se habían llenado de falsos pastores que con absurdos lamentos y quejas de todo tipo la maldecían y denostaban sin tener nada que ver con ella, leemos:

Entre estos disparatados, el que muestra que menos y más juicio tiene es mi competidor Anselmo, el cual, teniendo tantas otras cosas de qué quejarse, sólo se queja de ausencia; y al son de un rabel, que admirablemente toca, con versos donde muestra su buen entendimiento, cantando se queja.

¿Dónde reside, pues - podríamos preguntarnos-, la anunciada tragedia de esta historia? $\mathrm{O}$, ciñéndonos a la frase con que el proprio Eugenio se corrige: ¿en qué se basa para predecir un final tan desastroso como el que predice? Como hemos visto, en ningún momento nos lo deja presagiar su propia actitud, más bien resignada. $\mathrm{Y}$, sin embargo, en contra de lo que hubiéramos esperado, tampoco nos lo deja presagiar esa descripción que hace de Anselmo, del que llega a decirnos que, teniendo "tantas otras cosas de qué quejarse, sólo se queja de ausencia»; es decir, que en sus canciones no hay sombra de reproche alguno ${ }^{3}$.

Así, pues, recapitulando, bien podríamos afirmar que también en esta historia, como en el caso de la de Grisóstomo y Marcela, hay algo que no cuadra. Y no cuadra -obsérvese bien- por el motivo justamente opuesto; pues si por un lado Grisóstomo se queja, en palabras de Vivaldo, de celos, sospechas (de las que, por lo demás, se dice "cierto») y ausencia, haciendo saltar así la coherencia del relato, Anselmo, por su parte, al no quejarse de todas esas cosas de las que bien hubiera podido lamentarse y que

${ }^{3}$ Lo que, dicho sea de paso, explicaría la afirmación inmediatamente anterior; es decir, que sea quien más juicio tiene -si comparado con el comportamiento delirante de los demás pastores- y al mismo tiempo quien menos lo demuestra, ya que, dado el carácter de su lamento, y aun concerniéndole tan de cerca los actos de Leandra, parece no haber visto en ella lo que los demás, incluido el proprio Eugenio, han visto con claridad meridiana: la traición de que ha sido víctima. 
en la canción llevan derecho a la amenaza de suicidio, es decir, al quejarse sólo de ausencia y comportarse, por tanto, de un modo tan anómalo, en realidad priva a la historia del carácter trágico con que Eugenio nos la había presentado. Todo lo cual nos hace sospechar que esa "canción desesperada» de Grisóstomo - si idéntica o no a la que hoy leemos en el libro, eso no podemos saber$\mathrm{lo}^{4}$-, en un momento precedente de escritura, y que podría coincidir con el efectivo desenlace trágico de la historia que nos cuenta Eugenio, bien podría haber sido de Anselmo; un pretendiente si no obligado, al menos 'no desobligado' - según nos dice el proprio Eugenio-, en perpetua rivalidad con su amigo, traicionado con un tercero y que, por si le faltara algún requisito, compone hermosas canciones.

Así, pues, si reunimos todos los indicios que han ido emergiendo en este análisis -es decir, los paralelismos entre las protagonistas, entre los familiares que las tutelan y entre los propios narradores-y los sumamos a estas últimas consideraciones, de las que se deduce fácilmente cómo para que ambos relatos resulten coherentes a Grisóstomo le 'sobra' justamente lo que le 'falta' a Anselmo; si reunimos, pues, todos estos datos y los amalgamamos en una explicación común, todo nos lleva a pensar que Cervantes debió escribir la historia de Grisóstomo y Marcela teniendo a la vista una versión de la de Anselmo y Leandra (la llamaremos ahora así) bastante diferente de la que hoy leemos en el libro.

Ahora bien: ¿qué otras cosas podemos deducir de esta operación? Pues, en primer lugar, el marcado interés que Cervantes muestra en ella por los personajes femeninos, ya que si ahora nos propone a dos protagonistas perfectamente definidas y antitéticas sin sustraer nada a Leandra (el personaje originario), en el caso de los personajes masculinos Cervantes se limita a construir la trágica trayectoria amorosa de Grisóstomo sustrayendo a Anselmo la «canción desesperada» y el trágico final que anuncia; es decir, reduciéndo a este personaje a su mínima expresión.

Mas no sólo se evidencia esto, porque si releemos con atención estas palabras de Eugenio a propósito de Leandra:

Guardábala su padre, y guardábase ella; que no hay candados guardas ni cerraduras que mejor guarden a una doncella que la del recato proprio.

- donde podemos ver un contrapunto crítico a la medida que más tarde su padre toma con ella (la de encerrarla en un monaste-

${ }^{4}$ Hay que decir a este propósito que Adolfo de Castro publicó una versión con variantes de esta misma canción en Varias obras inéditas de Cervantes, Madrid, 1874, pp. 177-185. 
rio)_, si releemos, pues, estas palabras, observaremos que la figura de Marcela no es sino el desarrollo - y la virtuosa demostración- de estas observaciones; como si en determinado momento Cervantes hubiera querido insistir en ello y conceder a esta idea - cuya expresión 'negativa' sería Leandra- un espacio más amplio en la novela creando el personaje 'positivo' de Marcela; es decir, un personaje que - como decíamos al principio- en realidad no constituye sino la contrafigura del de Leandra.

Por lo que no es difícil deducir cuál es la apuesta que Cervantes hace en esta operación respecto al tema que retoma en ella. Si ningún candado o guarda garantiza la virtud de la mujer - virtud que, por lo tanto, se revela siempre como una libre elecciónla honestidad femenina no necesita velos que la cubran ni rejas que la protejan. Es más: si vivida afirmativamente y al aire libre, se revela como el único camino capaz de hacer ganar a la mujer un territorio hasta entonces vedado para ella: el de la autonomía y la libertad. Una tesis - ni que decirlo tiene- que se opone frontalmente a la conciencia dominante de la época, según la cual la virtud femenina sólo podía, no ya preservarse, sino realizarse de dos únicas maneras: o en el matrimonio o en la clausura (y recuérdese a este propósito -insistimos- cómo Leandra, fácil presa de Vicente de la Roca, para poder casarse va a parar a un monasterio en espera de lavar su fama).

Hasta aquí, pues, la estrecha relación que mantienen entre sí estas dos historias. Ahora bien: si ambas - como todo parece indicar- expresan un mismo pensamiento ¿por qué Cervantes sintió la necesidad de insistir en el tema? -podríamos seguir preguntándonos-; o, en otras palabras: ¿cuál fue el motivo concreto que le llevó a escribir la historia de Grisóstomo y Marcela?

En nuestra opinión, la respuesta pasa por el Aminta de Tasso, un pequeño drama en verso de ambiente pastoril cuya fama se extendió rápidamente por Europa después de su publicación en 1581, y que Cervantes - que en el Quijote de 1615 demuestra conocerlo bien, pues alaba la traducción de Jáuregui ${ }^{5}$ - debió de haber leído -o releído- cuando ya tenía escrita la historia de Leandra.

Pero veamos por qué decimos esto. Para empezar, obsérvese el planteamiento del que parte dicha obrita:

DAFNE. Vorrai dunque pur, Silvia, / da i piaceri di Venere lontana / menarne tu questa tua giovanezza? / Nél dolce nome di madre udirai, / né intorno ti vedrai vezzosamente / scherzar i figli pargoletti? Ah cangia, / cangia, prego, consiglio, / pazzarella che sei.

${ }^{5}$ Lo hace en el capítulo LII. 
SilviA. Altri segua i diletti de l'amore, / se pur v'è ne l'amore alcun diletto: / me questa vita giova; e'l mio trastullo / è la cura de l'arco e de gli strali, / seguir le fere fugaci, e le forti / atterrar combattendo; e se non mancano / saette a la faretra o fere al bosco, / non tem'io che a me manchino diporti.

DAFNE. Insipidi diporti veramente / ed insipida vita: e s'a te piace, / è sol perché non hai provata l'altra ${ }^{6}$.

Este diálogo, que inaugura la primera escena del primer acto y que Silvia - de quien Aminta está perdidamente enamoradomantiene con su amiga Dafne, no sólo caracteriza ya a la perfección a la protagonista de la historia - una muchacha que, como Marcela, reivindica su condición de virgen-, sino que plantea con toda claridad el dilema contextual en el que va a desarrollarse el drama, ya que, frente a la insinuación de la amiga, que le presenta el matrimonio como el estado ideal de la mujer (y recuérdense aquí las 'honestas' intenciones de Grisóstomo), Silvia reivindica como tal estado el de su propia libertad. Ni más ni menos que como lo hace el personaje de Marcela.

Pero pasemos a la acción. Si prescindimos de Dafne y Tirsi - amigos respectivos de Silvia y Aminta- y del fauno que en la primera escena del segundo acto intenta poseer a Silvia - personajes todos ellos requeridos por el carácter teatral y dialógico de la obra- la trama de la pieza es muy sencilla, ya que sus versos se limitan a referirnos, por un lado el enamoramiento apasionado de Aminta, y por otro las constantes negativas con que Silvia le responde. Con lo que, también en este aspecto - hechas las salvedades que apuntamos-, todo parece proceder como en la historia de Grisóstomo y Marcela.

${ }^{6}$ Reproducimos las citas del Aminta en italiano porque las dos versiones que Jáuregui hizo de la obra las publicó, la primera en Roma en 1607, y la segunda, con sus propias Rimas, en Sevilla once años más tarde; por lo que resulta evidente que Cervantes leyó el texto en italiano. Hemos empleado para estas citas la edición de Francesco Flora, en Aminta e Rime, vol I, Torino, 1976. Por lo demás, reproducimos a pie de página para el lector castellano la segunda versión de Jáuregui editada por JOAQuín ARCE, Aminta, Madrid, 1970. Estos son los versos que corresponden a los que aquí citamos: «DAFNE.-¿Querrás, Silvia, en efeto, I sin los placeres de la hermosa Venus / pasar tus verdes y floridos años? / ¿Ni oirás el dulce nombre / de madre, ni verás los tiernos hijos / con apacible juego rodearte? / Muda, muda de intento, / simplecilla de ti, que no te entiendes. SILVIA.-Siga otra los contentos amorosos, / si es que hay en el amor algún contento; / yo de esta vida gusto, y mi deleite / es atender al arco y la saeta, / seguir la fiera fugitiva, y luego / aterrar combatiendo la más brava; / y mientras no faltaren / al bosque fieras y a la aljaba flechas, / a mí no temo que placeres falten. DAFNE.-Desabridos placeres / por cierto, y vida en todo desabrida, / que si agora te agrada, / es por no haber probado otra ninguna». 
Mas no sólo; porque, además de su común condición de enamorados rechazados, también la caracterización de los protagonistas masculinos muestra algunas coincidencias que en absoluto nos parecen anecdóticas. Léanse, si no, estos versos extraídos del diálogo que Aminta mantiene con Dafne en la segunda escena del tercer acto y dígase el lector qué le recuerdan:

Aminta. ... di che temi? / ch'io non m'uccida? Temi de'l mio bene.

DAFNE. Non disperare, Aminta, / ... /

AMINTA. Oimè, che mia salute / sarebbe il disperare, / poi che sol la speranza / è stata mia rovina; ed anco, ahi lasso, / tente di germogliar dentro a'l mio petto / sol perché io viva: e quale è maggior male / de la vita d'un misero com'io? ${ }^{7}$

Las coincidencias llegan hasta el punto de que Aminta -inducido por la falsa noticia de la muerte de su amada- decide darse muerte tirándose a un barranco y cumpliendo de este modo el mismo gesto que Grisóstomo anuncia en su canción desesperada: el del suicidio.

Así, pues, idéntico conflicto, idénticas caracterizaciones de los protagonistas e idénticos gestos en estas dos historias cuyas únicas diferencias parecen emerger - lo repetimos- de su carácter: teatral en el caso del Aminta, y narrativo -además de fuertemente contextualizado- en el caso de Grisóstomo y Marcela.

Hasta que llega el desenlace. Porque justamente ahí, en los desenlaces, se dan las diferencias. Veámoslas.

La primera que observamos es que, frente a la esterilidad del gesto de Grisóstomo - pues Marcela ni siquiera se conmueve con su muerte-, el gesto de Aminta se revela fecundo, ya que, al conocerlo Silvia, produce en ella un arrepentimiento que la lleva a descubrir su amor por él y a renegar de la severa honestidad que siempre ha opuesto a sus requerimientos. Véase, si no, este parlamento suyo dirigido a Dafne en la primera escena del cuarto acto:

Oimè, che tu m'accori!, e quel cordoglio / ch'io sento de'l suo caso inacerbisci / con l'acerba memoria / de la mia crudeltate, / ch'io chiamava onestate: e ben fu tale, / ma fu troppo severa e rigorosa. / Or me n'accorgo e pento ${ }^{8}$.

\footnotetext{
7 «AMinta.-... / Si temes que me mate, mi bien temes. DafNE.-¿Por qué te desesperas, / ... AMINTA.- iAy, triste yo, que mi salud sería / desesperar, después que la esperanza / mi destruición ha sido; y todavía / tienta reverdecer dentro del pecho / sólo para que viva! / Y al que es tan desdichado, / ¿qué más fiero tormento que la vida?»

${ }_{8}$ «Oh Dafne! Tú me afliges, / y el gran dolor que siento de su daño / se aumenta más con la memoria acerba / de mi rigor pasado, / que honestidad lla-
} 
Palabras totalmente opuestas a las del discurso de Marcela y refrendadas inmediatamente por el coro que las sigue.

La segunda diferencia está íntimamente ligada a la primera, y es que, mientras Tasso decide perdonar la vida a Aminta - cuya caída acaba en un montón de zarzas- para que los protagonistas de su historia se unan en el triunfo del amor, Cervantes como todo el mundo sabe- deja que Grisóstomo muera inútilmente subrayando de este modo, frente a la imperturbabilidad con que Marcela sigue defendiendo sus principios, el carácter absurdo de su hybris amorosa.

Así que, recapitulando una vez más: ¿qué podemos deducir de todo esto? Pues, en primer lugar, como insinuábamos, que Cervantes parece haber escrito la historia de Grisóstomo y Marcela en estrecha correlación con el Aminta. Mas no sólo; porque dado el tema que abordan las historias, dados los paralelismos señalados y dadas esas divergencias de los desenlaces, Cervantes parece haberla escrito en abierta polémica con lo que en este drama viene a postular Torquato Tasso, ya que si éste nos presenta la honestidad femenina como un doloroso obstáculo en el camino del amor (además de como un absurdo acicate del placer - y léase a este propósito el último coro de la obra-) conduciendo en última instancia a Silvia al matrimonio, Cervantes, confirmando a Marcela en sus propias elecciones y sustrayéndola al destino doméstico de Silvia, nos presenta la honestidad femenina - ya lo hemos visto más arriba - como una vocación afirmativa y un camino de libertad. Por lo que bien podríamos decir, no sólo que en lo concerniente a esta temática nuestro novelista se coloca en las antípodas de Tasso, sino que, adoptando una técnica identica a la que emplea con los personajes de Leandra y de Marcela - y recuérdese que todo forma parte de una misma operación - construye una historia de planteamiento similar a la del poeta sorrentino con el único objetivo de recalcar sus divergencias; es decir, para que quede claro hasta qué punto disiente de él.

Pero, por si quedara alguna duda sobre lo que aquí hemos postulado, añadiremos que hay otros dos lugares en el texto donde cremos se refleja claramente la lectura del Aminta por parte de Cervantes. Ambos se encuentran en el discurso sobre la Edad de Oro que don Quijote dirige a los cabreros ${ }^{9}$. Veámoslos.

maba, y fuelo cierto, / pero fue muy severa y rigurosa; / agora lo conozco, y me arrepiento".

${ }_{9}$ El principal estudio hasta el momento sobre las posibles influencias literarias detectables en este discurso lo ha realizado GEOFFREY STAGG en su erudito artículo "Illo tempore: Don Quixote's Discourse on the Golden Age, and its Antecedents», "La Galatea» de Cervantes, cuatrocientos años después (Cervantes y 
El primero son sus frases iniciales, que repiten la escansión sintáctica de los versos iniciales del coro de pastores con que Tasso aborda este topos literario en la segunda escena del primer acto. Pero veamos antes estos versos:

O bella età de l'oro / non già perché di latte / sen'corse il fiume e stillò mele il bosco; / non perché i frutti loro / ... / non perché nuvol fosco / ... / ma sol perché quel vano / nome senza soggetto, / quel'idolo d'errori, idol d'inganno, / quel che dal volgo insano / onor poscia fu detto / ...10

Obsérvese cómo se van desgranando las frases: después de la exclamación inicial y de la serie de negaciones que la sigue, el coro aborda el tema central del discurso - la honestidad- con una construcción adversativa.

Obsérvese ahora cómo empieza el discurso que pronuncia don Quijote:

Dichosa edad y siglos dichosos aquellos a quien los antiguos pusieron nombre de dorados, y no porque en ellos el oro, que en esta nuestra edad de hierro tanto se estima, se alcanzase en aquella venturosa sin fatiga alguna, sino porque entonces los que en ella vivían ignoraban estas dos palabras de tuyo y mío.

¿Podríamos aportar algo mejor que esta semejanza entre los dos arranques como prueba de lo presente que Cervantes tenía la lectura del Aminta cuando escribe los nuevos episodios pastoriles? Por lo demás, añadiremos que este eco no es una mera cuestión de detalle, como podría parecer; y no lo es porque Cervantes no está recordando en él unos versos cualesquiera, sino el comienzo de lo que constituye un auténtico resumen ideológico de la obra; es decir, los versos iniciales de un coro en el que, siguiendo la horma del que aparece en Il vendemmiatore de Tansillo, Tasso nos presenta la honestidad femenina como una de las peores lacras de nuestra edad, considerándola un simple obstáculo en la obtención espontánea del placer y haciéndola responsable de «che furto sia quel che fu don d'Amore ${ }^{11}$; es decir, de todos los males mora-

lo pastoril), ed. Juan Bautista Avalle-Arce, Newark, 1985, pp. 71-90. Sin embargo, y a pesar de la exhaustividad de su estudio - que lo hacen imprescindible para quien quiera ahondar en el estudio de esta página-, el profesor Stagg no llega a relevar lo que aquí expondremos.

10 "Oh bella Edad del Oro venturosa, / no porque miel el bosque distilaba / y de las fuentes leche se vertía / no porque dio sus frutos abundosa / ... / no porque relucía / ... / mas sólo porque entonces este vano, / vano y fingido nombre sin sujeto, / este ídolo de errores engañoso, / a quien la urbanidad y el vulgo insano / llamó después honor....

11 "que el don de amor se llame hurto". 
les que se producen en el terreno de Eros. Con lo que es evidente que cuando Cervantes escribe estas páginas tenía que tener bien presente, no sólo la obra, sino cuál era su mensaje; un mensaje al que responde como ya hemos visto.

Por lo demás, sólo así adquiere todo su sentido ese otro lugar donde decimos se refleja la lectura del Aminta, y que no es sino el primer fragmento con el que don Quijote aborda en su discurso el tema de la honestidad femenina, es decir, el único tema que aborda el coro de Tasso; un fragmento cuyo significado se completa frente a éste, y más concretamente frente a los siguientes versos:

Allor... / ... / la verginella ignude / scopria sue fresche rose / ch'or tien ne'l velo ascose, / e le poma de'l seno acerbe e crude; / e spesso in fonte $\mathrm{o}$ in lago / scherzar si vide con l'amata il vago ${ }^{12}$.

Pero leamos lo que dice don Quijote:

Entonces sí que andaban las simples y hermosas zagalejas de valle en valle y de otero en otero en trenza y en cabello $^{13}$, sin más vestidos que aquellos que eran menester para cubrir honestamente lo que la honestidad quiere y ha querido siempre que se cubra.

Una respuesta a Tasso, pues - lo repetimos-, donde podemos ver, no sólo cómo don Quijote, siguiendo una tradición consolidada (que - digámoslo de paso- en Italia se interrumpe con Il vendemmiatore), ve en la honestidad un valor que se remonta a aquella edad feliz, sino cómo (dado el contexto en que se encuentra $-\mathrm{y}$ aquí el pensamiento de Cervantes parece insinuarse claramente en las palabras de su héroe-) considera la conjunción entre libertad y honestidad el estado ideal de la mujer. Con lo que bien podríamos decir que, frente a la visión masculinista que Tasso muestra del amor, el fragmento constituye por sí mismo un alegato en favor de la libertad del sexo femenino; un alegato que, aunque puesto en boca de don Quijote, muestra una perfecta sintonía con el espíritu de que están impregnados el discurso y la figura de Marcela.

\footnotetext{
12 «Entonces... / ... / de velo ni embarazo / jamás cubrió sus rosas encarnadas / la pastorcilla, ni la pura frente; / desnudo juntamente / su blanco pecho y pomas delicadas; / y a menudo en el agua detenida / triscar se vió el amante y su querida».

${ }^{13}$ Esta primera afirmación, que en realidad no es la que contradice a Tasso, también encuentra su correspondencia en el mismo coro, en donde, hablando siempre de la honestidad, leemos unos versos más abajo: "tu raccogliesti in rete / le chiome a l'aura aperte» («tú en redes recogiste / las hebras de oro que trataba el viento»).
} 
Así pues, y concluyendo con estas reflexiones, todo parece indicar que Cervantes somete la materia pastoril a dos fases de elaboración diferentes: una, a la que pertenecería la primera versión de la historia de Leandra (en la que muy probablemente Anselmo amenazaba con suicidarse), y otra, posterior, en la que, como respuesta a Tasso, escribe, no sólo la historia de Grisóstomo y Marcela, sino el discurso de don Quijote sobre la Edad de Oro, ya que, como hemos visto, sus frases iniciales -y no sólo- muestran una estrecha relación con el Aminta.

Mas no todo acaba ahí, porque si incorporamos ahora a nuestro análisis ese dato ya adquirido por la crítica cervantista, y más concretamente por Geoffrey Stagg ${ }^{14}$, según el cual los episodios que hoy ocupan los capítulos XI, XII, XIII y XIV de la obra originariamente se encontraban, no donde ahora los leemos, sino entre las páginas de la sierra ${ }^{15}$; si consideramos, pues, ahora este dato y lo que fácilmente se deduce de él, es decir, la recontextualización que Cervantes realiza del material escrito como respuesta a Tasso, concluiremos que las fases de elaboración a que nuestro novelista somete la materia pastoril en el Quijote de 1605, ya no son sólo dos, sino tres. Por lo que intentaremos ver ahora cuál es el alcance de la tercera.

Para lo cual, y volviendo de nuevo al discurso sobre la Edad de Oro, señalaremos, en primer lugar, que el último que hemos comentado no es el único fragmento en el que don Quijote aborda el tema de la honestidad femenina. Veamos cómo vuelve a él un poco más abajo, después de haber hablado de la justicia y de los jueces:

Las doncellas y la honestidad andaban, como tengo dicho, por dondequiera, sola y señera, sin temor que la ajena desenvoltura y lascivo intento le menoscabasen, y su perdición nacía de su gusto y propia voluntad. Y agora, en estos nuestros detestables siglos, no está segura ninguna, aunque la oculte y cierre otro nuevo laberinto, como el de Creta; porque allí, por los resquicios o por el aire, con el celo de la maldita solicitud se les entra la amorosa pestilencia y les hace dar con todo su recogimiento al traste.

${ }^{14}$ "Cervantes revisa su novela (Don Quijote, I Parte)» Anales de la Universidad de Chile, n. 140, 1966, pp. 5-33.

${ }_{15} \mathrm{Y}$ baste recordar a este propósito la alusión que, hablando con Sancho, don Quijote hace en el capítulo XXV a las palabras con que Ambrosio justifica la "canción desesperada» de Grisóstomo - «que, como ya oíste decir a aquel pastor de marras, Ambrosio, quien está ausente todos los males tiene y teme»-; frase de la que se deduce fácilmente que la historia de Grisóstomo y Marcela debía precederla muy de cerca. 
(Fragmento después del cual nuestro caballero se propone como defensor de dichas doncellas).

Varias cosas habría que comentar en este pasaje. En primer lugar, el desorden sintáctico de sus primeras frases, un aspecto en el que siempre han reparado los anotadores del Quijote. ¿Cómo explicárnoslo? En nuestra opinión no es muy difícil. Para empezar, obsérvese esa personalización a que Cervantes somete los conceptos de «honestidad», «ajena desenvoltura» y «lascivo intento", un recurso que, dejando a un lado «las doncellas» con que la frase empieza, los amalgama estrechamente en una serie de palabras homogéneas. Eliminemos ahora esa desinencia de plural del imperfecto «andaban», es decir la «n», y observemos cómo la frase que obtenemos con estos elementos es totalmente correcta: «la honestidad andaba, como tengo dicho, por dondequiera, sola y señera, sin temor que la ajena desenvoltura y lascivo intento le menoscabasen». ¿Qué podemos deducir de ello? Pues que en principio ésa era la frase original y que sólo posteriormente, en una reelaboración de ella, Cervantes introduce «las doncellas», la «n» requerida por el nuevo sujeto - ahora en plural-y todo el resto del fragmento - que en realidad sólo se entiende si referido, no a «la honestidad», sino a «las doncellas».

Así, pues, también aquí parecen insinuarse dos redacciones diferentes: una, a la que pertenecería esa frase que hemos 'rescatado' y que muestra una perfecta sintonía con el fragmento comentado más arriba (es decir, con la respuesta a los versos del Aminta), y otra, posterior, donde Cervantes introduce un evidente cambio de registro, pues - como es fácil observar- en ella la buena fe de su caballero ya no sintoniza con la filosofía de que está impregnado el discurso de Marcela, sino que constituye el vehículo para la sátira mordaz que, distanciándose de la voz del personaje, Cervantes dispara ahora contra un objetivo concreto. ¿Contra cuál? Pues, en nuestra opinión, contra un fenómeno habitual en la España de su tiempo: el de las beatas; mujeres que, invocando la virtud, se recogían en apartados lugares, a veces de clausura, para acabar haciendo en ellos lo que en los centros habitados no hubieran podido hacer sin ser observadas y que, en realidad, no constituyen sino la degeneración de la figura de la mujer autónoma, y supuestamente casta, que unas décadas antes habían encarnado algunas iluminadas como la respetadísima Francisca Hernández, por ejemplo ${ }^{16}$. Una sátira mordaz, pues, que

${ }^{16}$ Sobre el fenómeno de las beatas en tiempos de Cervantes véase la introducción de Stefano Arata a su edición de la comedia de LOPE DE VEGA El acero de Madrid, Madrid, 2000, pp 47-48. De las beatas iluminadas habla MARCEL BATAILLON en Erasmo y España, vol I, cap. IV, México D. F., 1950. 
Cervantes dirige ahora contra la hipocresía organizada en torno a la palabra honestidad.

Honestidad que, dicho sea de paso - y obsérvese que esto contradice abiertamente lo afirmado por la frase que hemos 'rescatado' y que Cervantes reelabora - ya no todas las doncellas de la Edad de Oro parecen apreciar como el bien irrenunciable del que sigue haciendo gala la castísima Marcela; un hecho que nuestro paladín de la virtud constata y -repárese en esa "perdición» con la que alude a él- sin duda desaprueba.

He aquí, pues, perfilarse algunos de los elementos que parece rijan esa tercera fase de elaboración de la materia pastoril en el Quijote; una fase en la que Cervantes, si bien no pierde totalmente de vista el objetivo que se había fijado ya cuando escribe la historia de Leandra, parece abandonar la técnica de los relatos ejemplares para adoptar la de la ironía propia de la sátira de costumbres, acentuando de este modo la distancia respecto a la voz de su caballero, de cuyas palabras - recuérdese bien- se había servido en la segunda fase para responder a los versos de Tasso.

Todo lo cual, y echando un vistazo retrospectivo al texto de la novela, nos induce a situar también en la tercera fase de elaboración de la materia las frases que Cervantes introduce en el capítulo IX a propósito de don Quijote cuando alude a su afición por las novelas pastoriles y al escrutinio que de ellas hace el cura en su librería. Pero leámoslas por extenso:

Por otra parte me parecía que, pues entre sus libros se habían hallado tan modernos como Desengaños de celos y Ninfas y pastores de Henares, que también su historia debería ser moderna [...]. Esta imaginación me traía confuso y deseoso de saber real y verdaderamente toda la vida y milagros de nuestro famoso español don Quijote de la Mancha, luz y espejo de la caballería manchega, y el primero que en nuestra edad y en estos tan calamitosos tiempos se puso al trabajo y ejercicio de las andantes armas, y al desfacer agravios, socorrer viudas, amparar doncellas, de aquellas que andaban con sus azotes y palafrenes, y con toda su virginidad a cuestas, de monte en monte y de valle en valle; que si no era que algún follón, o algún villano de hacha y capellina, o algún descomunal gigante las forzaba, doncella hubo en los pasados tiempos que, al cabo de ochenta años, que en todos ellos no durmió un día debajo de tejado, se fue tan entera a la sepultura como la madre que la había parido.

¿Por qué decimos que las observaciones que hacíamos a propósito del segundo fragmento con que don Quijote aborda el tema de la honestidad femenina en su discurso sobre la Edad de Oro nos inducen a situar estas frases en la tercera fase de elaboración de la materia pastoril? Pues, en primer lugar, porque, tocando el mismo tema, están escritas en el mismo registro que aquéllas 
-lo que establece entre estos dos fragmentos una relación de recíproca respondencia-; y en segundo, porque, dadas las alusiones que contienen, su eficacia hubiera sido más que dudosa si Cervantes las hubiera escrito cuando los episodios pastoriles todavía estaban en la sierra; es decir, a catorce o quince capítulos de distancia. Porque hay que señalar aquí -como en su momento anotó Javier Blasco ${ }^{17}$ - que este fragmento no sólo está en relación con lo que en el discurso sobre la Edad de Oro se dice de la honestidad femenina, sino con la propia historia de Marcela. A lo que, por nuestra parte, añadiremos algo más; y es que, si considerado en la óptica de nuestro análisis, en realidad contiene ya la clave de lectura de esa operación que Cervantes realiza trasladando a su lugar definitivo los episodios pastoriles de la sierra, pues - digámoslo desde ahora- todo parece indicar que dicho traslado está orientado al redimensionamiento de la figura de la pastora.

Pero veamos por qué afirmamos esto: observe ahora el lector, después de que Cervantes realiza este traslado, cuál resulta ser la nueva contrafigura de Marcela: no otra que Maritornes; una sierva de posada deforme y maloliente que practica el sexo a oscuras en un camaranchón con el primer arriero que se lo solicita, y que, apareciendo como aparece en el capítulo XVI, encontramos a un capítulo de distancia del discurso de Marcela ${ }^{18}$.

Ahora bien; si analizamos la caracterización que Cervantes hace de este personaje a lo largo de la novela, nos encontraremos con algunas sorpresas. Veamos, pues, en primer lugar, cómo nos la presenta cuando don Quijote y Sancho llegan a la venta:

Servía en la venta, asimesmo, una moza asturiana, ancha de cara, llena de cogote, de nariz roma, del un ojo tuerta y del otro no muy sana. Verdad es que la gallardía del cuerpo suplía las demás faltas: no tenía siete palmos de los pies a la cabeza, y las espaldas, que algún tanto le cargaban, la hacían mirar al suelo más de lo que ella quisiera.

Por si el retrato no fuera suficiente, y a medida que el capítulo avanza, la descripción de «la asturiana» — pues así la denomina también el narrador- sigue abundando en una serie de detalles parecidos y culmina, cuando don Quijote la recibe a oscuras en sus brazos, de este modo:

${ }^{17}$ En su comentario al cap. XI de la edición del Quijote dirigida por FRANCISco RIco, Volumen complementario, Barcelona, 1998, pp. 41-43.

${ }_{18}$ Aunque enhebrando la observación en otro tipo de argumento, también José Ángel Ascunce Arrieta pone en relación a ambos personajes y sus correspondientes episodios en su artículo "Valor estructural de las digresiones narrativas en la Primera Parte del Quijote», Anales Cervantinos, XIX, 1981, pp. 1-27. 
Y era tanta la ceguedad del pobre hidalgo, que el tacto, ni el aliento, ni otras cosas que traía en sí la buena doncella, no le desengañaban, las cuales pudieran hacer vomitar a otro que no fuera el arriero.

La caracterización del personaje no puede ser, pues, más grotesca; hasta el punto de que el lector percibe en ella, no a un personaje real, sino una caricatura. Ahora bien; si acudimos a todos los otros lugares donde aparece Maritornes a lo largo de la novela (y aparece, además de en estas escenas, en los capítulos XVII, XXVII, XXXII, XXXV, XXXVII, XXXVIII, XLIII, XLIV, XLV y XLVII) observaremos que en ninguno de ellos encontramos el más mínimo reflejo de esta terrible descripción.

¿A qué puede responder este dato? - nos preguntamos. ¿Al hecho de que Cervantes consideró la caracterización del capítulo XVI suficiente como para plasmar en nosotros la imagen del personaje? Puede ser. $\mathrm{Y}$ sin embargo hay un detalle que no nos convence en esta respuesta, y es el hecho de que en el resto de los capítulos ni siquiera aparezca el adjetivo "asturiana»; un adjetivo que en el capítulo XVI aparece, no una, sino siete veces y con el que el narrador - ya lo hemos dicho- llega incluso a denominarla. La pregunta que nos hacemos es, pues: ¿por qué no aparece dicho adjetivo ni siquiera una vez en todos los otros capítulos, cuando -insistimos - aparece siete veces en el capítulo XVI?

Para responder a esta pregunta haría falta que nos preguntáramos, a su vez, por el significado de dicho adjetivo; que, en nuestra opinión, y dado el conjunto de caracterizaciones lingüísticas de los personajes de la novela (recuérdense la inenteligibilidad de la lengua del vizcaino, o el refinamiento de la del canónigo de Toledo) querría decir simplemente 'persona con muy mal castellano' (es decir, con muy mala capacidad de expresión), ya que en Asturias se hablaba el bable.

Ahora bien; si, como vemos, la descripción de Maritornes es la contrafigura de la descripción de Marcela (autónoma, hermosa y virgen) ¿a qué rasgo de la pastora podría oponerse éste? Pues evidentemente al de su elocuencia, que en su discurso se manifiesta en ese despliegue de silogismos con que deja boquiabierto a su auditorio.

En conclusión: ¿qué intentamos decir con esto? Pues intentamos hacer ver simplemente que si el adjetivo "asturiana» está en relación inversa con la elocuencia con la que se expresa Marcela - como parece-, si resulta, pues, significativo justamente por esa correspondencia implícita que mantiene con ella, Cervantes debió introducirlo donde lo introdujo después de haber trasladado los episodios pastoriles desde la sierra hasta el lugar que hoy ocupan, 
es decir, después de haber puesto frente a frente a Maritornes y a Marcela, ya que de otro modo hubiera resultado gratuito; y contra dicha gratuidad - ya lo hemos dicho- testimonian esas siete veces que aparece en el capítulo.

Con lo cual, y siendo éste el rasgo que con mayor insistencia aparece en la caracterización de Maritornes, la respuesta a las dos preguntas que nos hacíamos más arriba parece evidente: el adjetivo "asturiana» y los rasgos con que Cervantes describe a Maritornes en el capítulo XVI no vuelven a aparecer a lo largo de toda la novela porque Cervantes los introduce aquí en correspondencia con la tercera fase de elaboración de la materia pastoril y para crear justamente esta nueva contrafigura de la pastora ${ }^{19}$.

Pero, apurando el razonamiento: ¿qué es lo que persigue Cervantes a través de ese juego de espejos que propone al lector y en el que sitúa ahora a estos dos personajes? Pues si tenemos en cuenta que la actual caracterización de Maritornes nace como un simple reflejo invertido de las cualidades de Marcela, es decir, que lo que aquí hace Cervantes no es más que invertir la figura de esta última obteniendo con ello un personaje inverosímil de puro grotesco, no nos será difícil deducir, a través de ese juego de reenvíos que la novela nos propone, cuál es el nuevo estatus de la pastora si contemplada en el nuevo contexto en que Cervantes la coloca: el de un personaje, a fuerza de bello y virtuoso, tan inverosímil como lo es la Maritornes del capítulo XVI, es decir, su propia contrafigura.

Y no sólo. Porque si consideramos todo lo que se nos cuenta en este capítulo, observaremos cómo la operación no parece afectar solamente a Marcela sino al conjunto de su historia, ya que todo lo que Cervantes narra en él parece una inversión grotesca de lo que hemos leído poco antes; véase, si no, el arriero -figura arquetípica de la persona malhablada-, que parece ser la contrafigura del refinado poeta que demuestra ser Grisóstomo; por no hablar de cómo sucumbe al instinto del bajo vientre ese paladín de la honestidad que poco antes pretendía ser don Quijote y que, después de haber contemplado en plena luz del día a la distante y hierática virgen Marcela, ahora recibe a Maritornes en la más negra oscuridad.

Con lo que, retomando la observación que hacíamos más arriba, todo parece concordar con el fragmento que aparece en el

${ }^{19}$ Un hecho, éste, que bien pudiera quedar corroborado por el dato de que don Quijote se cura la oreja que pierde en su lucha con el vizcaíno, no ya en la venta - como sin duda hubiera tenido que hacer antes de la operación de traslado de los episodios pastoriles-, sino en la majada; lo cual demuestra que la actual materia del capítulo XVI está reelaborada. 
capítulo IX, donde veíamos cómo en la tercera fase de elaboración de la materia pastoril Cervantes se chancea de su hidalgo y de esas doncellas vírgenes y libres que él está dispuesto a defender a toda costa.

Para acabar, dos observaciones nos sugiere este cambio de registro con que Cervantes aborda ahora el tema de la honestidad femenina y a sus propios personajes. La primera es una marcada concomitancia con el espíritu del diálogo erasmista Proci et Puellae; un diálogo en cuya primera mitad, y antes de pasar a hablar de las condiciones que un buen matrimonio requiere -matrimonio frente al que queda fuertemente redimensionada la «preciosa joya de la virginidad ${ }^{20}$-, María y Pamphilo desmontan con una buena dosis de ironía recíproca - de la que no está excluido el retrato caricatural ${ }^{21}$ - los tópicos literarios de la «muerte de amor»y de la "virgen homicida»22, es decir los tópicos en torno a los que gira la historia de Grisóstomo y Marcela.

La segunda, en fin, es la distancia que nuestro novelista parece tomar en esta operación, guiada sin duda alguna por la lectura de este colloquio, respecto al género pastoril; un género que, si bien le había servido para expresar ciertas ideas - y véase aquí su polémica con Tasso-, en realidad, y sobre todo si comparado con la obra que estaba escribiendo, debió de parecerle anquilosado,

\footnotetext{
${ }^{20}$ Obsérvese, como botón de muestra, este fragmento del diálogo: «MARía.-..., en opinión de todos muy favorable es la virginidad. PAMPHILO.-Yo confiesso que una donzella virgen es una preciosa joya; mas qué monstruo puede ser mayor que una virgen vieja? Si tu madre no oviera perdido aquella flor, no te alabaras tú dessa que tienes». M. MenÉndez Pelayo, Colloquios de Erasmo, Orígenes de la novela, Tomo IV, N.B.A.E.. 21, Madrid, 1915, p. 169

${ }^{21}$ Obsérvese a este propósito la descripción que Pamphilo hace del personaje de quien acaba enamorándose una de esas doncellas después de haber matado de desdenes a un apuesto enamorado: "La cabeza ahusada, pocos cabellos remolinados, comidos, mal peynados; más caspa e liendres en ellos que arenas ay en la mar; dessollado e arrugado el cuero como de raposa vieja sarnosa; los ojos hundidos y retirados, en tal manera que, quando piensas que mira adelante está mirando atrás. Las narices romas y retorcidas hazia arriba; la boca grande, no muy llena de dientes, y essos podridos; tartajoso; la barba llena de lepra. Una gran giba en las espaldas; el vientre de hydrópico; las piernas estecadas, delgadas e tuertas». Colloquios, p. 167. ¿Cómo no pensar aquí en el retrato de Maritornes?

${ }^{22}$ Hablando de este diálogo, ya Marcel Bataillon observaba en él esa «ironía sobre el estado de virginidad, tesoro precioso del que no se puede hacer mejor uso que perderlo". Op. cit., vol. I, p. 336. Por lo demás, Alban K. Forcione en "La Gitanilla and Erasmus's Colloquy on Courtship», Cervantes and the Humanist Vision: A Study of Four Exemplary Novels, Princeton University Press, 1982, pp. 113-136, demuestra hasta qué punto La Gitanilla está imbuida del modelo de este diálogo. Lo cual, si bien indirectamente, creemos refuerza nuestra observación.
} 
rígido y lleno de fórmulas caducas. Por lo que no es de extrañar que -y obsérvese que el fragmento que comentábamos del capítulo IX comienza con el recuerdo de este hecho- al final decidiera incluir las novelas pastoriles en el escrutinio de la librería de su hidalgo, reservándoles así el mismo trato que el cura concede en él a los libros de caballerías. 